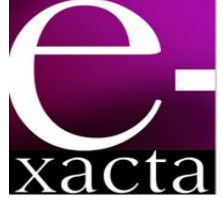

ISSN: 1984-3151

\title{
Comportamento do Concreto Mediante a AdiçÃo de POZOLANA ARTIFICIAL
}

\author{
Behavior of Concrete by the Addition of Artificial Pozzolan
}

\author{
Nathália Maria Assi Rabelo; Christianne Rodrigues Garcia² \\ 1 Bacharel em Engenharia Química. Centro Universitário de \\ Belo Horizonte, 2012. Belo Horizonte, MG. \\ narabelo@terra.com.br. \\ 2 Mestre em Engenharia Metalúrgica e de Minas. UFMG, \\ 1998. Professora do Centro Universitário de Belo Horizonte \\ - UniBH. Belo Horizonte, MG. cg.rodrigues@hotmail.com.
}

Recebido em: 21/02/2013 - Aprovado em: 20/04/2013 - Disponibilizado em: 11/06/2013

RESUMO: A utilização de resíduos minerais vem sendo empregada na indústria do concreto, trazendo vantagens em âmbitos técnicos, econômicos e ambientais. Ao substituir o cimento por esses resíduos, há a redução do consumo de energia e poluição do ar, gerados por sua produção e, ainda, contribui na busca por concretos de alto desempenho. Nesse contexto, o presente trabalho teve como objetivo adicionar pozolana artificial ao concreto e determinar a resistência à compressão, assim como a sua trabalhabilidade, além de estabelecer um comparativo entre o concreto adicionado de pozolana artificial e o concreto sem adição, contendo somente o cimento Portland. Através de ensaios laboratoriais, observou-se que a pozolana, devido a características específicas, não apresentou resultados favoráveis. Em sua adição ao concreto, observou-se que a quantidade de água necessária para a realização dos ensaios foi maior, alterando assim a relação água/cimento, sendo consequentemente necessário um aumento da quantidade de cimento. Observou-se, também, que houve uma queda na resistência à compressão do concreto, devido à presença da pozolana. Verificou-se que o material estudado necessita de modificações em suas propriedades para a sua utilização como insumo do concreto, portanto novas pesquisas, com um maior número de ensaios, foram sugeridas para determinar a sua viabilidade.

PALAVRAS-CHAVE: Pozolana artificial. Concreto. Resistência à compressão.

ABSTRACT: Mineral waste has been used in the concrete industry, bringing advantages in technical fields, economic and environmental. By replacing the cement by these residues eventually reduce energy consumption and air pollution generated by their production and also help in the search for high performance concrete. In this context, the present study aimed to add artificial pozzolan to concrete and to determine the compressive strength, as well as its workability, and establish a comparison between the concrete and artificial pozzolan added without adding concrete containing only Portland cement. Through laboratory tests, it was observed that the pozzolan, due to specific features, showed no favorable results. In its addition in concrete, it was observed that the amount of water required for the tests was greater, thus altering the water / cement ratio, and is therefore required an increased amount of cement. It was also observed that there was a decrease in the compressive strength of concrete due to the presence of pozzolan. It was found that the studied material requires changes in its properties for use as an input of the concrete, thus further research, with a greater number of tests have been suggested to determine their viability.

KEYWORDS: Artificial pozzolan. Concrete. Compressive strength. 


\section{INTRODUÇÃo}

O concreto é atualmente um dos materiais mais utilizados para a construção civil, juntamente com o aço, sendo composto de areia, brita, água, cimento Portland e aditivos. Porém, com o intuito de melhorar certas características, como resistência, durabilidade e trabalhabilidade, existe a necessidade da utilização de outros materiais na sua composição. (CORÓ, 2002)

A pozolana é desses materiais, sendo muito utilizada no processo de fabricação do cimento, apresentando características que the favorecem em suas diversas aplicações. De acordo com a NBR 12653 (ABNT, 1992), o material pozolânico é definido como: silicosos ou silicoaluminosos que possuem pouca ou nenhuma atividade aglomerante. No entanto, quando separados finamente e misturados à água, reagem com hidróxido de sódio formando assim compostos ligantes.

A adição de pozolana diretamente ao concreto tem como objetivo substituir parcialmente o cimento buscando melhorias nas propriedades e um menor custo final do concreto.

O objetivo geral do presente trabalho é determinar certas características do concreto adicionado de pozolana, com os objetivos específicos de determinar a variação da resistência à compressão e a trabalhabilidade do concreto.

Os ensaios realizados na Supermix Concreto S/A foram: resistência à compressão e trabalhabilidade, de acordo com as normas indicadas pela Associação Brasileira de Normas Técnicas (ABNT).

\section{CONCRETO}

O concreto é o material estrutural mais importante utilizado na construção civil atualmente. Ele foi descoberto no final do século XIX e o seu uso foi intensificado no século $X X$, o que o transformou no material mais consumido pela humanidade depois da água (HELENE; ANDRADE, 2010).

O concreto foi aprimorado com o tempo e ainda hoje é estudado para obtenção de características e propriedades específicas para cada tipo de aplicação.

Ele deve conter cimento, água e agregados com a possibilidade do emprego de aditivos, pigmentos, fibras especiais e adições minerais. A proporção entre esses componentes é estudada pela tecnologia do concreto para atender simultaneamente às propriedades mecânicas, físicas, durabilidade e a trabalhabilidade (HELENE; ANDRADE, 2010).

Existem duas fases distintas para esse material de construção, a primeira é denominada de concreto fresco e é compreendida entre $1 \mathrm{~h}$ e $5 \mathrm{~h}$ após a mistura. A segunda fase é denominada de concreto endurecido, na qual se inicia o endurecimento do concreto.

\subsection{Propriedades do Concreto Fresco}

A fase de concreto fresco refere-se ao tempo necessário para a mistura, transporte, lançamento e adensamento do concreto. As propriedades pertinentes a essa fase são a trabalhabilidade e a consistência.

\subsubsection{TRABALHABILIDADE}

A trabalhabilidade é definida como a aptidão para o manuseio e é influenciada pelos seguintes fatores: tipo de mistura, transporte, lançamento, adensamento, dimensões de peças e afastamento das armaduras. Essa característica está diretamente ligada à consistência. (BAUER; FALCÃO, 2000)

e-xacta, Belo Horizonte, v. 6, n. 1, p. 55-66. (2013). Editora UniBH. Disponível em: www.unibh.br/revistas/exacta/ 


\subsubsection{CONSISTÊNCIA}

A consistência é a maior ou a menor capacidade que o concreto tem em se deformar sob a ação de sua própria massa. (HELENE; ANDRADE, 2010)

Os fatores que influenciam a consistência são: relação entre água e agregados secos, granulometria e forma dos grãos do agregado, aditivos, clima e temperatura. (BAUER; FALCÃO, 2000)

\subsection{Propriedades do Concreto EnduRECIdo}

A fase do concreto endurecido refere-se ao processo do início da hidratação do cimento e está em constante evolução, prolongando-se por toda a vida útil do concreto. (HELENE; ANDRADE, 2010)

As propriedades que se encontram nessa fase são: resistência à compressão, massa específica, dilatação térmica, resistência à tração, elasticidade, permeabilidade e durabilidade. (BAUER; FALCÃO, 2000)

\subsubsection{RESISTÊNCIA À COMPRESSÃO}

A resistência à compressão é determinada de acordo com o tipo de cimento utilizado e com a aplicação do concreto. É determinada através do ensaio indicado pela NBR 5739 (ABNT, 2007).

\subsubsection{MASSA ESPECÍFICA}

A massa específica do concreto endurecido deve estar entre $2000 \mathrm{~kg} / \mathrm{m}^{3}$ e $2800 \mathrm{~kg} / \mathrm{m}^{3}$, de acordo com a NBR 6118 (ABNT, 2007).

\subsubsection{DiLATAÇÃo TÉRMICA}

A dilatação térmica depende da natureza e do teor de agregados presentes na pasta de concreto. O coeficiente de dilatação térmica segundo a NBR 6118 (ABNT, 2007) apresenta o valor de $\alpha=10^{-5} /{ }^{\circ} \mathrm{C}$, para efeito de análise estrutural.

\subsubsection{RESISTÊNCIA À TRAÇÃO}

A resistência à tração do concreto é obtida através do ensaio de compressão diametral, descrito na NBR 7222 (ABNT, 1994)

\subsubsection{ELASTICIDADE}

O módulo de elasticidade do concreto é determinado por meio do ensaio descrito segundo a NBR 8522 (ABNT, 2008). Ele apresenta as seguintes variáveis que podem interferir em seu valor: resistência à compressão, consistência, teor de umidade dos corpos de prova durante o ensaio, dimensão máxima do agregado miúdo, temperatura do ensaio e natureza

\subsubsection{DURABILIDADE}

A durabilidade das estruturas de concreto está diretamente ligada ao grau de exposição à deterioração. Tais processos do concreto dependem de determinados agentes como apresentado na Tabela 1. 
Tabela 1

Agentes agressivos ao concreto

\begin{tabular}{|c|c|}
\hline AGENTES & REAÇÃO NO CONCRETO \\
\hline Mecânicos & $\begin{array}{l}\text { Abrasão, choques, vibração e } \\
\text { fadiga e o concreto não resiste a } \\
\text { impactos. }\end{array}$ \\
\hline Físicos & $\begin{array}{l}\text { Alteração na temperatura gera } 0 \\
\text { aparecimento de trincas. }\end{array}$ \\
\hline $\begin{array}{l}\text { Ecológicos/ } \\
\text { Químicos }\end{array}$ & $\begin{array}{l}\text { Utilização de água contendo } \\
\text { sulfatos e agentes radioativos, } \\
\text { causando microfissuração e, } \\
\text { dependendo do agente químico, } \\
\text { desintegração do concreto. }\end{array}$ \\
\hline Biológicos & $\begin{array}{l}\text { As bactérias promovem a síntese } \\
\text { de ácidos que dissolvem a cal } \\
\text { presente no concreto. }\end{array}$ \\
\hline
\end{tabular}

Fonte: BAUER; FALCÃO, 2000

\subsection{DOSAGEM DO CONCRETO}

A dosagem do concreto consiste na proporcionalidade mais econômica e adequada de seus materiais constituintes, para a obtenção de determinadas características. Cada material influencia na dosagem e na qualidade do concreto final.

A utilização excessiva do cimento pode gerar maior plasticidade, coesão, calor de hidratação, variação volumétrica e menor segregação e exsudação. $O$ aumento da quantidade de agregado miúdo gera um maior consumo de água, cimento e uma maior plasticidade. Os agregados graúdos influenciam de acordo com seu formato, se eles são mais arredondados e lisos, geram maior plasticidade e menor aderência. Se forem lamelares geram maior consumo de areia, cimento e água e menor resistência.

O formato ideal é o cúbico e rugoso, que favorece a aderência na pasta de cimento. (CURTI, 2009).

A dosagem pode ser feita por dois métodos mais conhecidos: O método $\mathrm{ACl}$ (American Concrete Institute) e o método ABCP (Associação Brasileira de Cimento Portland).

\subsubsection{MÉtodo de Dosagem ABCP}

$O$ método de dosagem $A B C P$ para agregados brasileiros é uma adaptação do método $\mathrm{ACl}$ que busca a obtenção de uma consistência fluida e plástica do concreto. Essa dosagem fornece a quantidade aproximada de materiais, devendo ser testada experimentalmente. (CURTI, 2009)

Para a execução da dosagem obtém-se, inicialmente, as características dos materiais que serão utilizados, em seguida deve-se fixar a relação água/cimento, determinar o consumo de materiais e expressar o traço.

É necessário conhecer primeiramente o tipo de cimento que será utilizado, sua massa específica e a sua resistência à compressão aos 28 dias. É indispensável também realizar a análise granulométrica dos agregados - para determinar o módulo de finura do agregado miúdo, a dimensão máxima do agregado graúdo e a massa específica e unitária compactada de ambos. (CURTI, 2009).

Conhecendo-se as especificidades dos materiais, deve-se determinar as características desejadas do concreto. Sendo elas: a consistência no estado fresco, as condições de exposição do concreto e a resistência de dosagem aos 28 dias.

Em seguida, fixar a relação água/cimento em função da Curva de Abrams (curva que compara a relação água/cimento com a resistência mecânica do cimento) do composto utilizado (CURTI, 2009).

Por fim, determina-se o consumo de cada material, através das características obtidas anteriormente. 


\subsubsection{MÉTOdO de DOSAGEM UTILIZADO}

O método de dosagem utilizado no presente trabalho foi uma adaptação do método ABCP. Ele consiste na realização de traços com relações água/cimento prédeterminadas, sendo elas: 0,$45 ; 0,55 ; 0,65 ; 0,70 ; 0,75$; 0,85; 0,95 e 1,05. Essas relações água/cimento são utilizadas para a criação da curva de Abrams, que é empregada para a determinação da resistência à compressão de cada fator água/cimento, indicando assim qual deles deve ser usado para o tipo de concreto desejado.

\section{Pozolana}

O material pozolânico pode ser caracterizado como artificial e natural. De acordo com a NBR 12653 (ABNT, 1992), pozolana natural é aquela de origem vulcânica ou de origem sedimentar com atividade pozolânica. Já a pozolana artificial é definida como um material proveniente do tratamento térmico ou subproduto industrial também com atividade pozolânica.

Além da caracterização de sua origem, o material pozolânico é dividido em três classes, N, C e E, de acordo com a NBR 12653 (ABNT, 1992). A classe N corresponde às pozolanas naturais e artificiais como certos materiais vulcânicos de caráter ácido, silicosos, argilas calcinadas e terras diatomáceas.

A classe $C$ é composta por cinzas da queima de carvão mineral proveniente de termelétricas, e a classe $\mathrm{E}$ refere-se às pozolanas que apresentam características diferentes das demais classes.

No presente trabalho utilizou-se a pozolana artificial de argila calcinada, resíduo proveniente da extração de zinco, portanto classificada como $\mathrm{N}$, conforme a norma anterior.

\section{Metodologia}

\subsection{MATERIAIS}

Os ensaios foram realizados com os seguintes materiais: a pozolana artificial, o cimento, a água e os agregados.

A pozolana artificial foi um material doado para a pesquisa, recebido no mês de maio/2012. Ela é proveniente da indústria de galvanização situada no município de Três Marias - MG. Trata-se de um resíduo do processo de extração de zinco através da sua mineração.

O cimento empregado foi o CPV RS fabricado pela Holcim. Ele apresenta alta resistência à compressão aos sete dias e resiste ao ataque de sulfatos. A água utilizada foi a proveniente da Companhia de Saneamento de Minas Gerais (COPASA).

Os agregados miúdos e graúdos seguem as exigências estabelecidas na NBR 7211 (ABNT, 2009), que se refere aos padrões de granulometria, substâncias nocivas e propriedade físicas.

\subsection{ENSAIOS}

\subsubsection{DeterminaçÃo DA AtIVIDADE POZOLÂNICA}

A NBR 5752 (ABNT, 1992) rege a determinação do índice de atividade pozolânica no cimento Portland. O ensaio para a determinação desse índice na pozolana artificial utilizada no presente trabalho foi uma adaptação ao citado pela norma.

Os equipamentos usados para a realização do ensaio foram: balança com precisão de 0,1 g; armassadeira para a mistura da massa; colher de pedreiro; moldes cilíndricos e haste para adensamento.

e-xacta, Belo Horizonte, v. 6, n. 1, p. 55-66. (2013). Editora UniBH. Disponível em: www.unibh.br/revistas/exacta/ 
A seguir constam as etapas realizadas no ensaio:

1. Primeiramente houve a pesagem dos materiais. Utilizou-se a massa composta pela areia quatro frações, cimento CPV RS, pozolana artificial e água;

2. As misturas foram realizadas em diferentes proporções de cimento e de pozolana, sejam as quais: $0 \%, 15 \%, 20 \%, 25 \%$ e $35 \%$ de pozolana e o restante de cimento. Essas proporções foram definidas a partir do limite máximo estabelecido pela NBR 5752 (ABNT, 1992) e deduzidas aleatoriamente;

3. Para cada uma das misturas moldou-se três corpos de prova, sendo que a moldagem foi realizada em quatro camadas, cada uma delas com 30 golpes com a haste de adensamento;

4. Realizou-se então a cura dos corpos de prova e o rompimento à sua compressão com a idade de vinte e oito dias.

\subsubsection{DeterminaçÃo da MASSA Específica e DA FinURA DA POZOLANA}

A massa específica e a finura da pozolana artificial estudada foram determinados através de ensaios realizados pela $A B C P$, Associação Brasileira de Cimento Portland, devido à especificidade dos equipamentos que deveriam ser utilizados para tais fins. As normas que regem esses ensaios são: NBR NM 23 (ABNT, 2001) e a NBR NM 76 (ABNT, 1998).

\subsubsection{Preparação do Concreto em LABORATÓRIO}

De acordo com a NBR 12821 (ABNT, 2009), os equipamentos utilizados para a preparação do concreto em laboratório devem ser: balanças para medir a massa de cada material; misturados, no caso betoneiras para homogeneizar os traços e a mistura de materiais; utensílios e ferramentas para o manuseio do concreto e dos materiais e cronômetro.

Os materiais estudados foram: agregados graúdos e miúdos; material cimentício que consta da mistura de $25 \%$ de pozolana artificial e $75 \%$ do cimento CPV RS e a água nas suas devidas proporções. Essa dosagem foi especificada através do ensaio da determinação da atividade pozolânica.

Os procedimentos de ensaio consistem nas seguintes etapas:

1. Introduz-se na betoneira em movimento de rotação o agregado miúdo e graúdo;

2. Adiciona-se parte da água de amassamento;

3. Após, no máximo, um minuto a partir do início do funcionamento da betoneira, deve-se interromper a mistura e adicionar a massa cimentícia

4. Aciona-se novamente a betoneira e adicionase a água restante. O tempo de mistura é contado a partir da adição da água;

5. É recomendado o descanso da massa por três minutos para observar a trabalhabilidade e possíveis ajustes na mistura.

\subsubsection{Abatimento do Tronco de Cone}

De acordo com a NBR NM 67 (ABNT, 1998), os equipamentos utilizados para a realização desse ensaio devem ser: haste de seção circular, reta, feita de aço, para a realização da compactação; régua; placa de base feita de aço para apoio do molde; molde de aço para corpo de prova do ensaio. As medidas são de acordo com a Figura 1 apresentada. 


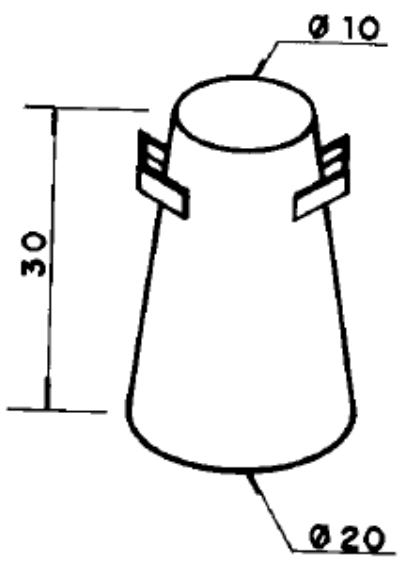

Figura 1 - Dimensões do tronco de cone. Fonte: ARAÚJO; RODRIGUES; FREITAS, 2010.

Os procedimentos para a realização do ensaio foram os seguintes:

1. Inicialmente umedece-se o molde e a base, em seguida inicia-se o preenchimento do molde com concreto. Durante o preenchimento o operador deve posicionar seus pés sobre as aletas de forma que mantenha o molde estável;

2. Preenche-se o molde com três camadas, sendo cada uma delas com aproximadamente um terço da altura total do molde;

3. Compacta-se cada camada com 25 golpes provenientes da haste; deve-se uniformizar os golpes sobre a seção de cada camada;

4. Limpa-se a placa de base e retira-se cuidadosamente $\mathrm{o}$ molde de concreto levantando-o na direção vertical. A operação de retirada deve ser realizada entre 5 e 10s;

5. Após a retirada do molde, deve-se medir o abatimento do tronco do concreto através da diferença entre a altura do molde e a altura do eixo do corpo de prova, que corresponde à altura média do corpo de prova moldado. A medida do abatimento está representada na Figura 2.

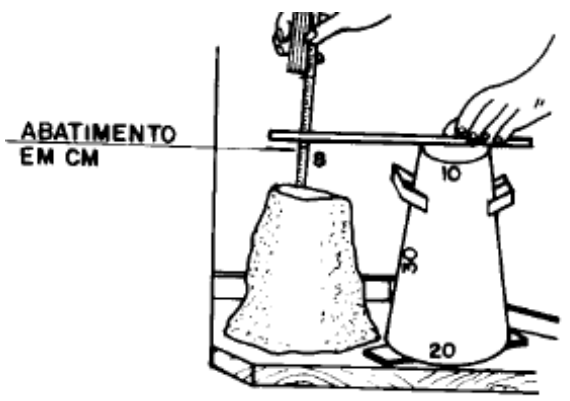

Figura 2 - Medida do abatimento do tronco de cone. Fonte: ARAÚJO; RODRIGUES; FREITAS, 2010.

\subsubsection{Moldagem E CuRA dos Corpos DE Prova de Concreto}

De acordo com a NBR 5738 (ABNT, 2003), a aparelhagem utilizada para a moldagem e cura dos corpos de prova de concreto devem ser: molde cilíndrico com altura igual ao dobro do diâmetro; haste para adensamento; câmara úmida para a realização da cura; retífica para o faceamento dos corpos de prova e colher de pedreiro.

O ensaio engloba os seguintes procedimentos:

1. Antes do procedimento de moldagem deve-se revestir os moldes e suas bases com uma camada fina de óleo mineral;

2. Adiciona-se o concreto no molde com o diâmetro de $15 \mathrm{~mm}$. Ele é adicionado em três camadas, cada uma delas sendo

3. adensada manualmente com a haste com vinte e cinco golpes;

4. A última camada é adensada com excesso de concreto para ser totalmente para que ocorra o mesmo dentro do molde; 
5. Deve-se vibrar cada camada de concreto, utilizando a haste de adensamento como elemento vibrante;

6. A última camada necessita da realização do rasamento da superfície utilizando-se uma colher de pedreiro adequada;

7. O procedimento de cura acontece logo após a moldagem dos corpos de prova. Eles precisam ser transportados até a câmara úmida e permanecer lá até sua idade de rompimento;

8. Atingindo a idade de rompimento os corpos de prova passam pela retificação, que consiste na retirada mecânica de uma fina camada do topo do corpo de prova.

\subsubsection{Ensaio de Compressão dos CoRPos de Prova de Concreto}

O ensaio de compressão dos corpos de prova de concreto é regido pela norma NBR 5739 (ABNT, 2007). Ela determina que os equipamentos utilizados para esse ensaio sejam: prensa, utilizada para a determinação da carga de compressão aplicada ao corpo de prova até sua ruptura, e um paquímetro.

O ensaio é constituído das seguintes etapas:

1. O corpo de prova depois de moldado de acordo com a NBR 5738 (ABNT, 2003) e aguardada a sua idade de ruptura, que pode ser 1, 3, 7 ou 28 dias, tem sua altura e o diâmetro do corpo de prova determinados;

2. As faces do corpo de prova são acertadas através de uma retífica, para que não haja falsos resultados;

3. Centraliza-se o corpo de prova nos pratos da prensa e inicia-se o carregamento contínuo e sem choques, como indicado na Figura 3.
4. O carregamento só cessa quando houver indícios de ruptura do corpo de prova, como mostra a Figura 4.

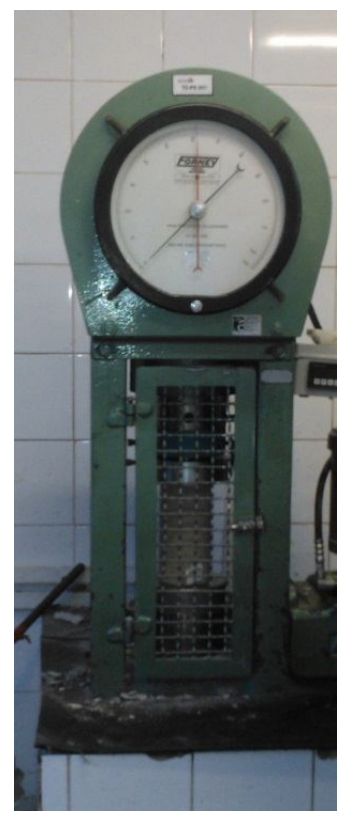

Figura 3 - Prensa para a realização do ensaio

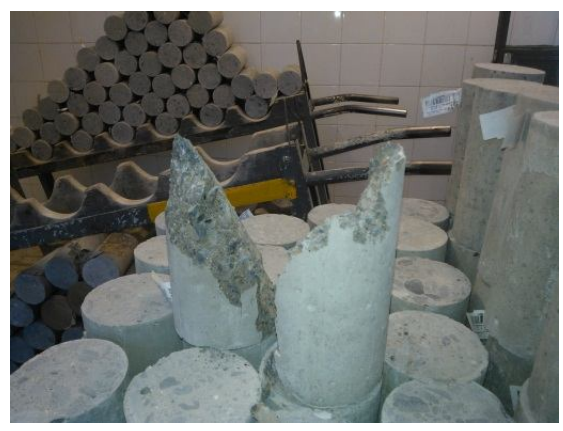

Figura 4 - Corpo de prova após o rompimento

\section{Resultados e Discussões}

\subsection{Caracterização da Pozolana Artificial}

Os ensaios realizados pela $A B C P$ apresentam as características físicas da pozolana estudada e estão apresentados na Tabela 2. 
Tabela 2

Caracterização da Pozolana Artificial

\begin{tabular}{c|c}
\hline ENSAIO & RESULTADOS OBTIDOS \\
\hline $\begin{array}{c}\text { Massa Específica } \\
\begin{array}{c}\text { Finura pelo método } \\
\text { de Blaine }\end{array}\end{array}$ & $2,55 \mathrm{~g} / \mathrm{cm}^{3}$ \\
\hline & $11200 \mathrm{~cm}^{2} / \mathrm{g}$ \\
\hline
\end{tabular}

Observa-se que a finura da pozolana artificial é muito grande quando comparada com a do cimento ensaio pelo mesmo método. A finura do cimento é cerca de $400 \mathrm{~cm}^{2} / \mathrm{g}$, constatando que a pozolana é um material muito fino, podendo intervir nos resultados obtidos.

Os resultados da determinação do índice de atividade são representados de acordo com a resistência à compressão dos corpos de prova aos 28 dias, os quais a Tabela 3 indica, referentes a cada mistura ensaiada.

Tabela 3

Índice de Atividade Pozolânica

\begin{tabular}{c|c}
\hline MISTURA & RESULTADOS OBTIDOS \\
\hline $\begin{array}{c}\text { 100\% Cimento } \\
\text { 15\% Pozolana }+85 \% \\
\text { Cimento }\end{array}$ & $50,2 \mathrm{Mpa}$ \\
$\begin{array}{c}\text { 20\% Pozolana }+80 \% \\
\text { Cimento }\end{array}$ & $36,6 \mathrm{MPa}$ \\
$25 \%$ Pozolana $+75 \%$ \\
$\begin{array}{c}\text { Cimento } \\
\text { 35\% Pozolana }+65 \% \\
\text { Cimento }\end{array}$ & $30,6 \mathrm{MPa}$ \\
\hline
\end{tabular}

De acordo com a NBR 5752 (ABNT, 1992), a atividade pozolânica deve ser de no mínimo $75 \%$ da resistência à compressão do cimento aos 28 dias.

O valor mínimo esperado seria de 37,6 MPa para uma mistura de pozolana artificial e cimento. $O$ percentual que apresentou valor mais próximo foi o de $15 \%$ de pozolana. Porém essa porcentagem apresenta um baixo índice de resistência à compressão, o que o torna inviável economicamente.

Então optou-se pela utilização de $25 \%$ de pozolana na mistura, pois reduz o consumo de cimento, o que a torna economicamente favorável.

\subsection{Caracterização do Concreto}

\section{Adicionado de Pozolana Artificial}

\subsubsection{AvaliaÇão do Concreto No Estado Plástico}

A avaliação do concreto no estado plástico consiste na análise do consumo de água da massa de concreto para se obter o mesmo valor de abatimento do tronco de cone. No caso, o valor desejado era de $12 \mathrm{~cm}$.

A demanda de água foi analisada na mistura do concreto com resistência esperada de $30 \mathrm{MPa}$ aos 28 dias, bombeável. A Tabela 4 demonstra um comparativo entre o consumo de água do concreto com $25 \%$ de pozolana e o concreto somente com cimento.

Tabela 4

Caracterização do concreto no estado plástico

\begin{tabular}{c|c|c}
\hline MISTURA & $\begin{array}{c}\text { DEMANDA DE } \\
\text { ÁGUA }\end{array}$ & $\begin{array}{c}\text { ABATIMENTO DO } \\
\text { TRONCO DE CONE }\end{array}$ \\
\hline $100 \%$ Cimento & $201 \mathrm{~L} / \mathrm{m}^{3}$ & $12 \mathrm{~cm}$ \\
\hline $\begin{array}{c}25 \% \text { Pozolana } \\
+75 \% \text { Cimento }\end{array}$ & $225 \mathrm{~L} / \mathrm{m}^{3}$ & $12 \mathrm{~cm}$ \\
\hline
\end{tabular}

Através da Tabela 4 pode-se notar que o consumo de água do concreto adicionado de pozolana foi maior para a mesma consistência desejada. É necessário o aumento do consumo de água em $24 \mathrm{~L} / \mathrm{m}^{3}$, para que sejam mantidas as mesmas características de 
resistência mecânica com esse aumento de água. É preciso também aumentar o consumo de material cimentício em aproximadamente $35 \mathrm{~kg} / \mathrm{m}^{3}$, utilizandose uma relação água/cimento igual a 0,7 . Isso ocorre devido à diferença de finura entre os materiais observada anteriormente. A Figura 5 apresenta 0 resultado do ensaio de abatimento do tronco de cone.

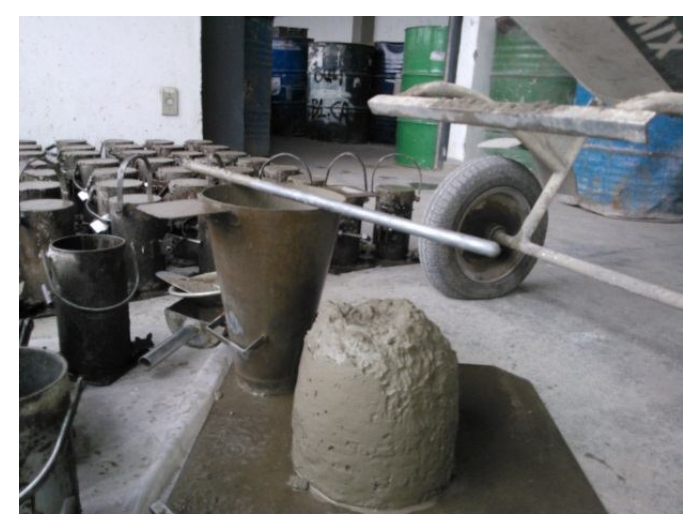

Figura 5 - Abatimento do tronco de cone

\subsubsection{Avaliação do Concreto no Estado ENDURECIDO}

O concreto no estado endurecido foi avaliado através da realização de uma curva de relação água/cimento pela resistência à compressão do concreto, cuja curva está apresentada na Figura 6.

O gráfico indica os resultados de resistência à compressão para as idades de 3, 7 e 28 dias.

Outra análise do estado endurecido foi a realização da comparação da curva da mistura de concreto contendo pozolana com a curva da mistura contendo somente cimento. A Figura 7 demonstra 0 gráfico comparativo da resistência à compressão aos 28 dias de idade.

Observa-se pelo gráfico a diferença significativa entre as resistencias à compressão para a mesma relação água/cimento quando comparadas as duas curvas.

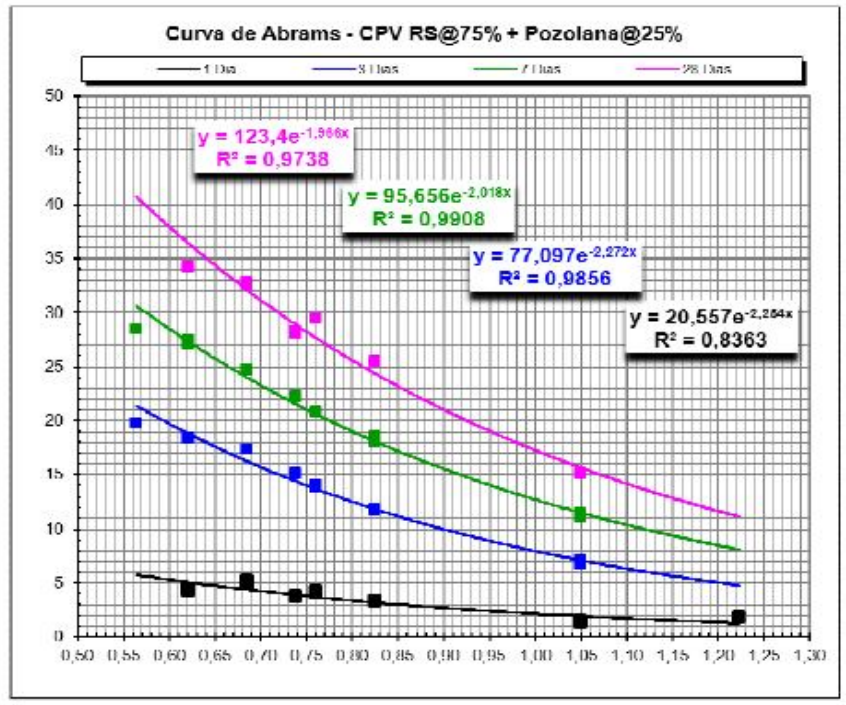

Figura 6 - Curva relacionando a relação água/cimento com a resistência à compressão

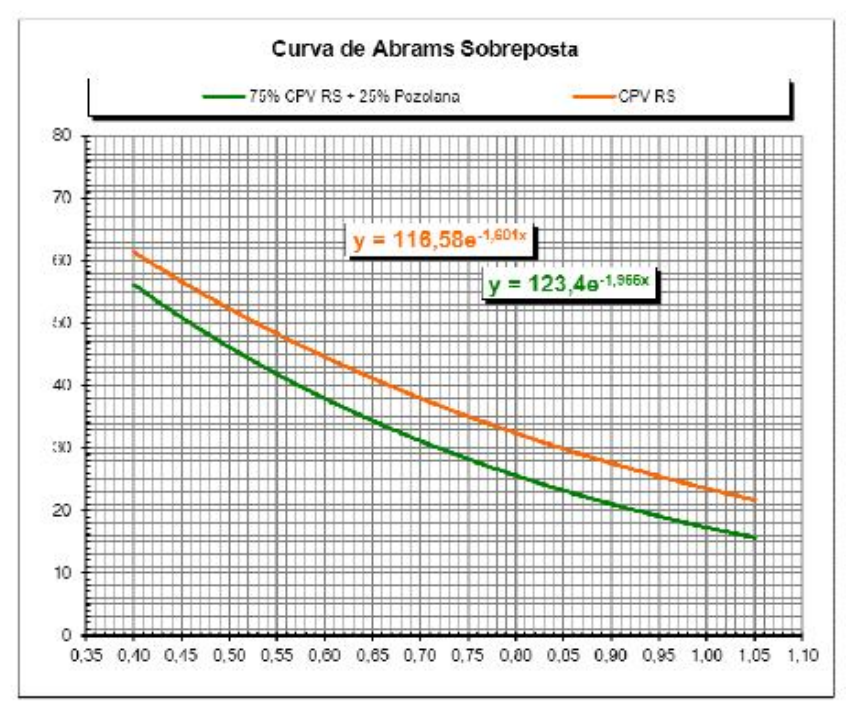

Figura 7 - Curvas comparativas

\subsubsection{ANÁlise do Consumo Médio de Material Cimentício}

Comparando-se o consumo médio de um concreto com resistência mecânica esperada de $30 \mathrm{MPa}$, bombeável, relação água/cimento 0,7 , tem-se a variação da quantidade de material cimentício representada na Tabela 5. 
A diferença de consumo é de $86 \mathrm{~kg} / \mathrm{m}^{3}$, uma vez que a mistura com pozolana exige maior quantidade de material cimentício para a manutenção da resistência mecânica.

Tabela 5

Avaliação do consumo médio de material cimentício

\begin{tabular}{c|c}
\hline MISTURA & $\begin{array}{c}\text { QUANTIDADE DE MATERIAL } \\
\text { CIMENTÍCIO }\end{array}$ \\
\hline $\begin{array}{c}100 \% \text { Cimento } \\
\text { Cimento }\end{array}$ & $284 \mathrm{~kg} / \mathrm{m}^{3}$ \\
\hline Pozolana $+75 \%$ & $370 \mathrm{~kg} / \mathrm{m}^{3}$ \\
\hline
\end{tabular}

\section{CONCLUSÕES}

O objetivo do presente trabalho era determinar as características referentes ao concreto adicionado de pozolana artificial. Através dos resultados dos ensaios realizados, observou-se uma queda considerável na resistência à compressão do concreto. Considerando os demais ensaios realizados, pode-se perceber que a diminuição dos valores de resistência mecânica comparada com o concreto comum deve-se ao alto valor da finura do material, interferindo diretamente na quantidade de água necessária para a realização do traço. O aumento da quantidade do líquido acarreta uma diminuição da resistência mecânica e, para a sua manutenção, deve-se aumentar o consumo de material cimentício. Para a utilização da pozolana artificial ser viável relativamente ao consumo de materiais, deve-se reduzir a sua finura e realizar novamente os testes.

\section{AGRADECIMENTOS}

As autoras agradecem à Supermix Concreto S/A, onde foram realizados os experimentos.

\section{REFERÊNCIAS}

ARAÚJO, L.; RODRIGUES, R; FREITAS, F. Concreto de Cimento Portland. São Paulo, 2010.

ASSOCIAÇÃO BRASILEIRA DE CIMENTO PORTLAND - ABCP. Ensaios para a caracterização da pozolana. Belo Horizonte, 2012.

ASSOCIAÇÃO BRASILEIRA DE NORMAS TÉCNICAS. NBR 6118 - Projeto e execução de obras de concreto armado. Rio de Janeiro, 2007.

ASSSOCIAÇÃO BRASILEIRA DE NORMAS TÉCNICAS. NBR 7222 - Argamassa e Concreto Determinação da resistência à tração por compressão diametral de corpos-de-prova cilíndricos. Rio de Janeiro, 2010
ASSOCIAÇÃO BRASILEIRA DE NORMAS TÉCNICAS. NBR 5739 - Concreto - Ensaio de compressão de corpos de prova cilíndricos. Rio de Janeiro, 2007

ASSOCIAÇÃO BRASILEIRA DE NORMAS TÉCNICAS. NBR 8522- Concreto - Determinação do módulo estático de elasticidade à compressão. Rio de Janeiro, 2000.

ASSOCIAÇÃO BRASILEIRA DE NORMAS TÉCNICAS. NBR 12653 - Materiais pozolânicos Especificações. Rio de Janeiro, 1992.

ASSOCIAÇÃO BRASILEIRA DE NORMAS TÉCNICAS. NBR 7211 - Agregados para concreto Especificações. Rio de Janeiro, 2005. 
ASSOCIAČÃO BRASILEIRA DE NORMAS TÉCNICAS. NBR 12821 - Preparação de concreto em laboratório. Rio de Janeiro, 2009.

ASSOCIAÇÃO BRASILEIRA DE NORMAS TÉCNICAS. NBR 7211 - Agregados para concreto Especificações. Rio de Janeiro, 2009.

ASSOCIAÇÃO BRASILEIRA DE NORMAS TÉCNICAS. NBR NM 67 - Concreto - Determinação da consistência pelo abatimento pelo tronco de cone. Rio de Janeiro, 1998.

ASSOCIAÇÃO BRASILEIRA DE NORMAS TÉCNICAS. NBR 5738 - Moldagem e cura de corpos de prova cilíndricos. Rio de Janeiro, 2003.

ASSOCIAÇÃO BRASILEIRA DE NORMAS TÉCNICAS. NBR 5739 - Ensaio de compressão de corpos de prova cilíndricos. Rio de Janeiro, 2007.

ASSSOCIAÇÃO BRASILEIRA DE NORMAS TÉCNICAS. NBR 5752 - Materiais Pozolânicos Determinação da atividade pozolânica com cimento Portland - Índice de atividade pozolânica com cimento. Rio de Janeiro, 1992.

ASSOCIAÇÃO BRASILEIRA DE NORMAS TÉCNICAS. NBR NM 23 - Cimento Portland e outros materiais em pó - Determinação da massa específica. Rio de Janeiro, 2001.

ASSOCIAÇÃO BRASILEIRA DE NORMAS TÉCNICAS. NBR NM 76 - Cimento Portland Determinação da finura pelo método de Blaine. Rio de Janeiro, 1998.

BAUER, L. A; FALCÃO. Materiais de Construção. 5 ed. Uberlândia-MG; Editora LTC, 2000.

CORÓ, Ângela Ghisleni. Investigação das propriedades mecânicas de concreto reforçado com fibras pet. ljuí, RS. 2002. 64 p.

CURTI, Rubens. Propriedades e Dosagem do Concreto. Recife, PE. 2009. 42 p. Disponível em: <http://www.abcp.org.br/comunidades/recife/download/ pm_minicursos/11_curso_intensivo/Dosagem.pdf $>$.

Acesso em: mai. de 2012.

HELENE, Paulo; ANDRADE, Tibério. Concreto de Cimento Portland. In: HELENE, Paulo, et.al. Materiais de Construção Civil e Princípios de Ciência e Engenharia de Materiais. 2 ed. São Paulo-SP. Editor Geraldo C. Isaia, 2012. Capítulo 29, 945 - 984 p. 